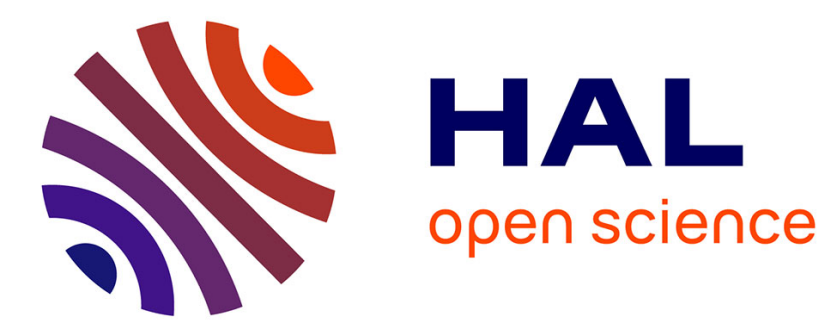

\title{
OpenBIM Based IVE Ontology: an ontological approach to improve interoperability for Virtual Reality Applications
}

Anne-Solène Dris, François Lehericey, Valérie Gouranton, Bruno Arnaldi

\section{- To cite this version:}

Anne-Solène Dris, François Lehericey, Valérie Gouranton, Bruno Arnaldi. OpenBIM Based IVE Ontology: an ontological approach to improve interoperability for Virtual Reality Applications. 35th CIB W78 Conference, Oct 2018, Chicago, United States. pp.1-10. hal-01900424

\author{
HAL Id: hal-01900424 \\ https://hal.science/hal-01900424
}

Submitted on 22 Oct 2018

HAL is a multi-disciplinary open access archive for the deposit and dissemination of scientific research documents, whether they are published or not. The documents may come from teaching and research institutions in France or abroad, or from public or private research centers.
L'archive ouverte pluridisciplinaire HAL, est destinée au dépôt et à la diffusion de documents scientifiques de niveau recherche, publiés ou non, émanant des établissements d'enseignement et de recherche français ou étrangers, des laboratoires publics ou privés. 


\title{
OpenBIM Based IVE Ontology: an ontological approach to improve interoperability for Virtual Reality Applications
}

\author{
Anne-Solene Dris ${ }^{1}$, Francois Lehericey ${ }^{2}$, Valerie Gouranton ${ }^{3}$, and Bruno \\ Arnaldi $^{3}$ \\ 1 Vinci Construction France, INSA Rennes, Inria, IRISA \\ 2 Vinci Construction France \\ 3 Univ. Rennes, INSA Rennes, Inria, IRISA, CNRS
}

\begin{abstract}
In this paper, we propose an ontology improving the use of Building Information Modelling (BIM) models as a virtual interactive environment (IVE) generator. The result is not only the ability to create a bidirectional link between the informed 3D database and the virtual reality application, but to automatically generate object-specific functions and capabilities according to their taxonomy. We present the results based on the Risk-Hunting training application. In this context, the notions of weight, object handles and, scheduling of the construction are essential for the immersion of the future trainee and educational success.
\end{abstract}

Keywords: Building Information Modeling (BIM), Ontology, Virtual and Augmented Reality, Interoperability

\section{Introduction}

\subsection{AECO in France, a sector highly exposed to occupational accidents}

The Architecture, Engineering, Construction and Owner-operated (AECO) industry is the most accident- prone sector in France. In 2014, 145 construction sector employees (excluding temporary workers) died while working in France. The construction industry employed $8.6 \%$ of employees and recorded $16.3 \%$ of "accidents with stop" and $26 \%$ of deaths. As for the causes of accidents, manual handling is by far the most challenged category, accounting for more than half of all work stoppages () with a rate of up to $53 \%$. Followings are falling full on foot with $13 \%$, falls from height with $12 \%$, and the use of hand tools with $9 \%$.

An economic approach to the question shows that their cost, globalized with that of occupational diseases, would amount to $1.3 \%$ of the national wealth, ie the theoretical equivalent of more than ten additional holidays on the calendar. These few figures illustrate the very dangerous nature of the sector and lead to an interest in the problem of accident prevention in construction. 


\subsection{Training, essential lever}

Various reasons can help to explain the difficulties that prevention poses in this sector of activity: risk factors are of human, technical, organizational, material and often interdependent origins. Statistics show that workers benefiting from reduced support in the company, including posted workers, foreigners, temporary workers or apprentices, are most prone to workplace accidents. As an example, mention can be made of the INRS report[1] which stipulates that accident victims of foreign origin (non-European) are three times more numerous in the building and civil engineering sector than in other sectors, the same is true for European foreign employees. These statistics highlight the lack of training and experience of these categories of workers, especially for foreigners, but also the lack of support for temporary workers, who change their job and work environment regularly. Even in large groups such as Vinci, which for many years has been conducting a comprehensive prevention policy with the "zero accident" plan, the difference in frequency rates between employees and temporary workers is still worrying.

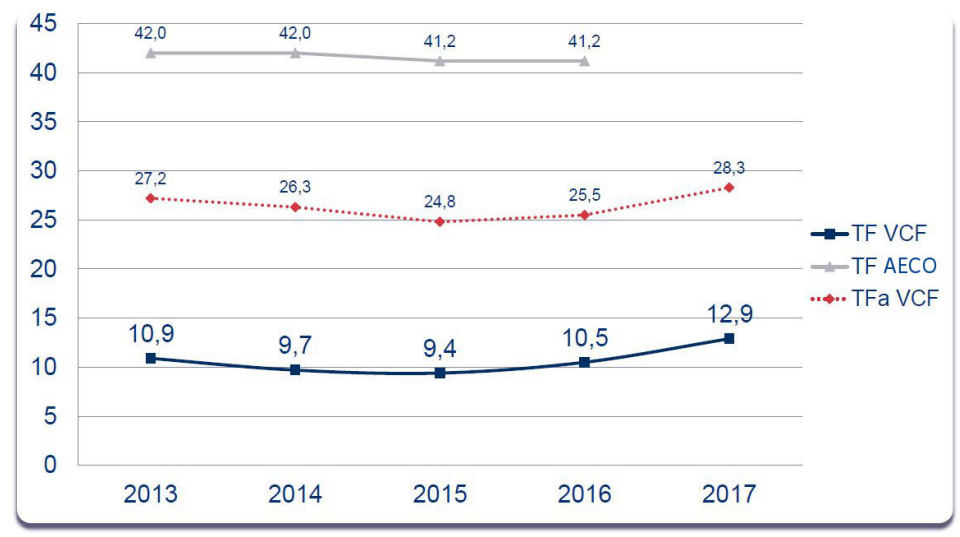

Fig. 1. Evolution of frequency rate $(\mathrm{TF})=$ (number of accidents in first settlement / hours worked) x 1,000,000.

One of the difficulties encountered in the management of training is related to temporary workers who do not always benefit from the same level of information and knowledge related to the materials and methods of construction specific to the site on which they intervene. Recent studies demonstrate the benefits of virtual reality training[3] compared to traditional training methods. But the costs involved are still high[4] in the case of virtual reality. In both cases, the training is sequenced and does not allow the real situation, each construction project is unique. However, the work environment has a considerable impact on the perception of risk and therefore on the behavior of employees. The arrival of BIM, a working process commonly used in the construction industry, makes it possible to obtain a virtual double of the act of building. 


\subsection{Goal}

The purpose of this study is to present a virtual reality training scenario generation method that allows the trainee to be immersed in the unique configuration of the site he / she is involved in.

\section{Related Works}

Overview Several reasons[5] explain the risky behaviour of the workers: the lack of knowledge of the safety rules, the lack of respect of these rules, a nonconducive environment such as high productivity targets, psychological factors, the pride of "hard leather" in male environments such as construction, lack of training, organization of the site and a sequencing of the tasks to be performed that do not take into account the needs of the workstation.

Traditional training in risk prevention / Training in virtual reality Virtual reality provides a relevant response to the act of training to perform tasks without dangers, train many people from different locations[6] at lower costs, understand abstract concepts or absolve from the language barrier (written or oral), and put into practice.

We also note that traditional training does not allow trainees to adapt to a changing environment[7] so immersion into a risk hunt in virtual reality (VR) can enrich learning.

In the particular case of risk prevention, the hazard reflex is the expected result. According to the work of JB Watson, the reflex can be conditioned by the senses and participates in the acquisition of knowledge[8] in humans. We agree with Sutherland's (1965) view that "the ultimate (virtual reality) device would be an environment in which the computer could control the existence of objects (and our interaction with them). The five senses can therefore be solicited simultaneously[9], which increases the interest and commitment of the participant[10] in his training thus improving the acquisition of knowledge. The limits of VR in relation to Real Education today are of a technical nature related to the use of a new technology: technical and professional skills of the developer, acceptability of interaction techniques by trainees not accustomed to video games, the orientation can be disrupted by the reduction of the field of vision and the movements whose latency can be problematic. We also remember that motion sickness can disrupt immersion in the interactive virtual environment (IVE).

\subsection{Generate the virtual world}

Costs Building a real-world simulation tool like Risk Hunting is comparable to flight simulators[11]: expensive and long. In the field of construction, using BIM as a support to generate the IVE[12] allows more flexibility and considerable cost reduction. 
Ontologies OpenBIM Based IVE, however, has its limits: the interaction and the definition of the objects on which it is possible to interact is not treated by the IFC (Industry Foundation Classes) standard. The development of an ontology meets the needs to enable the reuse[13] of knowledge of a specific area and to share a common structure of information. From the computing point of view, and more particularly knowledge engineering, the most commonly accepted definition is that of (Gruber, 1993): "an ontology is an explicit specification of a conceptualization of a domain". Conceptualization makes it possible to identify by an abstraction process the essential concepts referenced by the terms of the domain and the specification makes explicit the meaning associated with these concepts by associating them with a definition.

Few ontologies have been created for the construction sector; for information processing[14] a complete study of which has been presented by Issa and Mutis[15] in the description of BIM uses[16] and BIM objectives but also in asset management[18] and in the description of the field of action of BIM[19]. All these researches agree on the need for a field that is digitalized to develop these ontologies.

Contribution The interaction needs of VR have not yet been formally addressed and this is the part that our research addresses by proposing a specific domain[20] ontology. Focusing on the Noy\&McGuinness Seven-Step method based on Protege software, we offer a common working environment for interactive VR applications whose virtual environment is derived from OpenBIM.

\section{Proposed Solution and Results}

\subsection{The creation of ontologies}

Several methodologies have been proposed for the construction of ontologies. These methodologies propose to use different types of information media to start the ontology such as terminology databases, technical documentation, ontologies, interview reports, questionnaires. We can cite inter alia Cyc methods (Lena and Guha, 1990) and SENSUS (Swartout et al., 1997), the KACTUS approach (KACTUS, 1996), METHONTOLOGY methodologies (Gomez-Perez et al., 1996) and On-To-Knowledge (Staab et al., 2001). The process of building an ontology is composed of several phases such as described in Figure 1 (The life cycle of an ontology (Fernandez et al., 1997). The Seven Steps Method proposed by Noy \& McGuiness breaks down its activities as follows:

i. Determine the domain and the scope of the ontology.

ii. Consider reusing existing ontologies.

iii. Enumerate important terms of the ontology.

iv. Define the classes and the class hierarchy.

v. Define the properties of classes - slots.

vi. Define the facets of the slots.

vii. Create instances. 


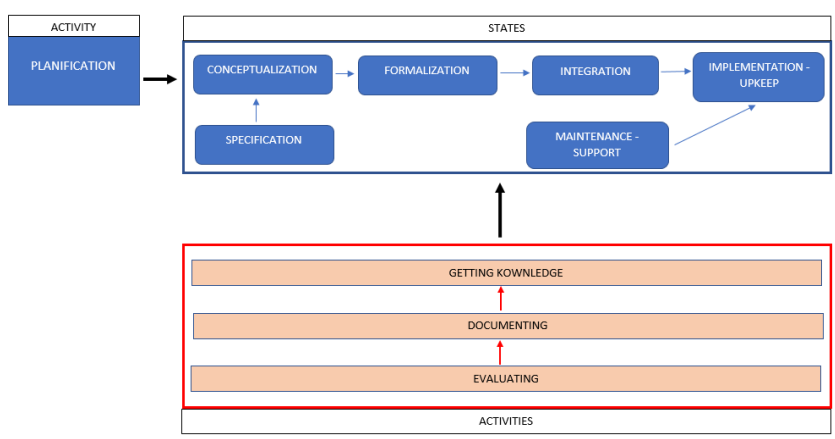

Fig. 2. Ontology Lifecycle

Steps iv to vii are repeated as many times as necessary in the ontologization process. In view of OpenBIM Based IVE ontology, the addressed domain is that of OpenBIM and interaction in virtual reality. We mainly used IFC ontologies[21] as the basis for project development. Working groups are currently collaborating to use these data and technologies to support their developments such as the buildingSMART Data Dictionary[22] (bSDD). We will therefore evolve the model with the results of their studies. The acquisition of knowledge of the domain is the phase allowing enumeration of the main terms of the domain. For this we have studied the numerous working documents, standards and processes of the various IVE general services as well as the existing Risk Hunting Courses and their specifications. Based on the Omniclass[23] table 35 - Tools in order to qualify object classes, we were then able to develop the properties inherent in the interaction such as the ability to grab an object and how it can be manipulated.

Example: Concrete bins are of the class IFCBuildingElementProxy with the Omniclass property number 35-51 31311151 which allows us to qualify the use of the object to which we add the definition of manual handles on which we can interact to move the object on wheels or the lifting hooks that the crane can use. These two properties have been developed with the ontology presented here.

The evaluation phase is continued on different virtual reality applications. In our case, we chose the Risk Hunting Course because it seems to us to be one of the most complete VR applications in terms of interaction with the virtual environment: moving around a building model, moving objects, collaborative work, note taking and exchange with the crane operator.

\subsection{Design of the application}

BIM models loading. A virtual Risk Hunting Course will be more meaningful to the companions following the training if it is based on the site to which they will be transferred or on which they currently work. Starting from this principle, up to eight BIM models will be used: BIM PIC corresponding to the model of the Bureau of Study of the Organization Methods of Construction site, which will make it possible to visualize the installation of the building site in the phases of 

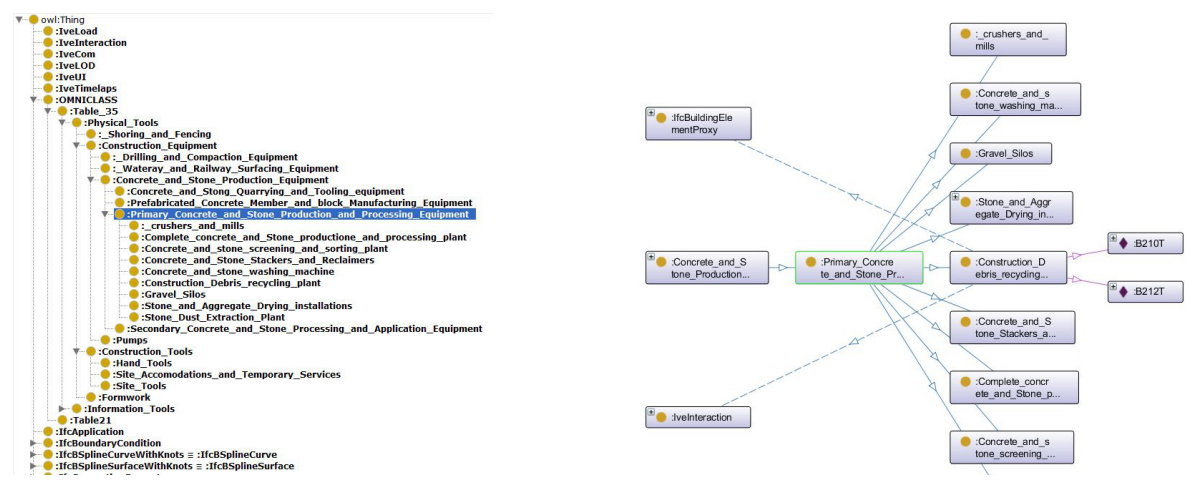

Fig. 3. OpenBIM based IVE Onthology - Protege

earthworks, infrastructure, superstructure and bodies of states. BIM ROT, the phased BIM model representing the cycle of rotation and construction logging of the building structure. To understand the ontology, this model is based on the BIM STR model of the structural design office and brings a higher level of detail (cutting the model) BIM MEX corresponding to the BIM model of the Bureau of Study of the Methods of Execution which is based on the BIM ROT model, and the BIM STR model and adds the necessary equipment for the security of the building, the shoring and the material formwork.

BIM STR which will be used by the different design offices;

BIM CEA, architectural lot model used for state body phase;

BIM ELE, execution model of the electricity design office;

BIM HVAC, execution model of the design office Heating, Ventilation, Air conditioning;

BIM PLB, execution model of the plumbing design office.

On these eight digital models, only the model of structure is necessary to the models of the methods but did not need to be loaded directly in the virtual environment of Risk Hunting. The seven other BIM models are loaded in IFC format in the game engine via the integrator.

Interactive Environment To display and interact with the virtual environment, we can use different kind of devices with varying degree of immersion. These devices include a screen mouse and keyboard, a head mounted display (HMD) or a CAVE ${ }^{\mathrm{TM}}$. We decided to use a HMD (HTC Vive) in our case because these kinds of system can be easily transported and deployed in training centres while allowing a good degree of immersion. The trainee wears a headset that cover his field of view and shows him the virtual environment and can move in a limited play-area by physically walking. The trainee also has two controllers to interact with the environment in a few different ways (shown in Figure 4): Walking and teleportation is used to navigate in the environment. The trainee can physically move in the play-area to navigate through the virtual environ- 
ment. The play-area being much smaller than the virtual environment, a second way of navigating through teleportation is implemented. By pointing with the left controller, the user is able to teleport (which move the play-area location in the virtual environment) to reach unattainable locations. Additionally, the trainee can use a hologram-map to see a miniature view of the building and directly teleport across the whole environment. Both the teleportation and the hologram map use the semanic of the IFC to know where the trainee is allowed to go and what to display in the hologram-map through filtering of IFC classes. As the IFC classes does not define the semantic of teleportation target areas, the filtering has to be done manually either by adding a custom property on the IFC objects or by manually listing which IFC classes can be teleprotation targets.
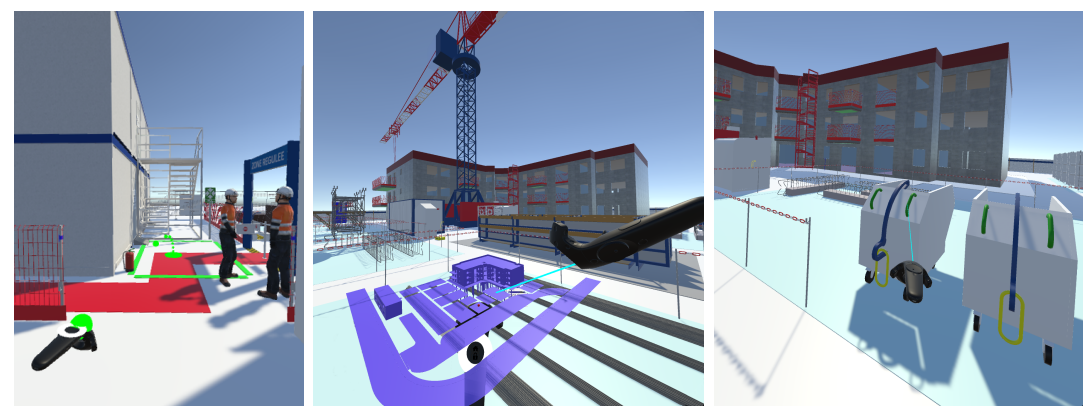

Fig. 4. Examples of the different ways to interact with the environment. From left to right: teleporting to a new location by pointing, teleporting to a new location by using the hologram-map and interacting with an object.

Use and grab objects. Some object in the scene are usable and interacting with them can trigger certain effects (e.g. interacting with a closed door will open it). To interact with an object, the trainee has to point it with the left controller and press the interact button. This method allows to interact with an object without having to physically reach it. We use the IFC properties to define which object are interactable and automatically add the interaction metaphor (similarly to teleportation). Additionally, we can define interactions on specific part of a IFC object by using sub-products to identify which area trigger which interaction. For example an concrete bins have a two type of interaction : The green parts trigger a manual interaction to move the bin whereas the yellow parts are used to hook the bin to the crane (see Figure 4). Also, some object in the scene are grabbable. These objects can be grabbed by pointing them with the right controller and hold the grab button. IFC properties can be used to automatically define which objects are grabbable by looking at their size and weight in the IFC properties.

Scenario To address the issue of reusability of the application, we build a model of Virtual Risk Hunting to self-generate randomly possible serious errors based 
on the integrated IFC. Thus, depending on the projects, the scenario adapts to it and proposes a different set of errors for each launch. To achieve this goal, we decomposed this problem in two parts : error insertion and error scriptwriting.

For error insertion, we defined different kind of errors to be automatically applied to the virtual environment. We rely on the ontology of the IFC to detect every possible occurrence of each error that can be applied in the environment (by adding, removing or modifying object in the scene). For example, by knowing the semantics of fixings, PTE platforms and walls, we can automatically misplace a fixing above an opening (see Figure 5).

For error scriptwriting, we write for each kind of error a scenario that define it's behaviour and how to correct it. Scenarios are defined with the \#SEVEN model[24] which is based on a petri net model and use sensors and effectors to handle the interaction with the environment. For the PTE platform example, we wrote a scenario where platforms collapse if the trainee don't fix the fixing position when he is close to the platform (see Figure 5). We use both the semantics of the IFC and the sensor/effector model of \#SEVEN to write generic scenario that can be applied generically to any situation. This is done by having custom sensor and effector that communicate with the IFC semantic.
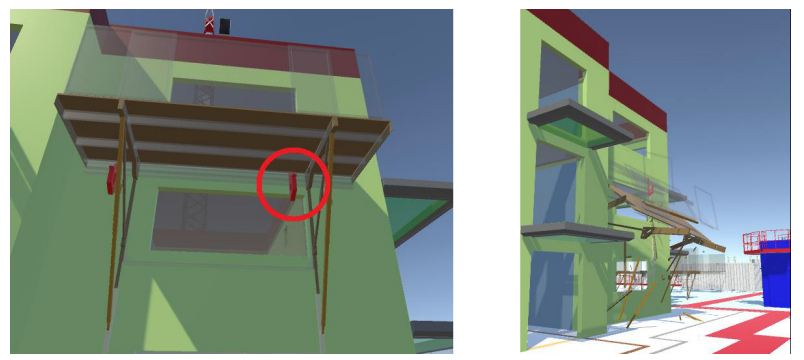

Fig. 5. Example of misplacement of fixings of PTE platform in the virtual environment. On the left, one fixing is misplaced (above an opening). On the right, this is what the trainee will see if he walks away from the PTE platform if he does not signal error.

Collaboration A collaborative virtual environment (CVE) [25] is an application that uses a virtual environment that supports human-computer-human communications. CVEs have many applications in medicine, architecture, learning or simply entertainment. In the context of prevention training, this option offers trainees and trainers a way to communicate and collaborate synchronously[26] and seamlessly. The BIM Collaboration format (BCF) was introduced following an idea from Tekla and Solibri to separate the communication of the messages describing the problems[27] discovered on the digital model from the model itself. Indeed, before the BCF was introduced, users who wanted to exchange data, conflict detection or modification requests on the model had to send the entire model. The receiver of the model had to compare it with the previous version to 
be sure to see all the changes. The BCF format allows you to attach comments, small portion of the BIM model and views, and create it as a virtual post-it.

Questionnaire Design During our research on the benefits that virtual reality can bring compared to traditional training methods, we have been faced with the problem of lack of existing studies. The return of the experiments carried out does not make it possible to establish a concrete result. If the finding seems clear about the benefits of this technology during the training, its interest in the long term remains to be proven. We therefore designed a questionnaire system based on three sheets. The first categorizes the trainee in terms of knowledge prior to training and in terms of technology. It is proposed in preamble to the formation. At the end of the training in VR, a second questionnaire makes it possible to evaluate the acquisition of knowledge according to the trainee's assessment. Then, a month later, the same questionnaire is submitted to them again. This test phase will be continued in the coming weeks.

\section{Conclusion and Future Works}

The various areas of AECO industry requiring the formalization of knowledge is still vast but through this study, we propose a solution improving the interoperability between virtual reality and OpenBIM, developing the works of BuildingSmart on the IFC, the bSDD, rankings and BCF in the field of VR.

In the future, it will possible to reiterate the ontology construction process by studying the implementation of the error creation system and the needs of the ontology by studying the actions of trainees during their training. We are also thinking of using it on other virtual reality applications by studying the possibility of co-activity, adding stress levels according to people's roles, and qualifying men's security objects in order to make them more effectives.

\section{References}

1. National Research and Safety Institute - INRS (2014) Statistiques Prvention. Available at: http://www.inrs.fr/actualites/statistiques-BTP-2014.html.

2. OPPBTP - Professional Organization of Prevention of Building and Public Works (2017). Les accidents de travail dans le BTP: quels sont les risques et comment les prvenir?

3. Ho, C. L. and Dzeng, R. J. (2010) Construction safety training via e-Learning: Learning effectiveness and user satisfaction, Computers and Education. Elsevier Ltd, 55(2), pp. 858867.

4. Gao, Y., Gonzalez, V. A. and Wing Yiu, T. (2017) Serious games vs. traditional tools in construction safety training : a review, 6(July), pp. 653660.

5. Choudhry, R. M. and Fang, D. (2008) Why operatives engage in unsafe work behavior: Investigating factors on construction sites, Safety Science, 46(4), pp. 566584.

6. Barot, C., Lourdeaux, D., Burkhardt, J. M., Amokrane, K., \& Lenne, D. (2013). V3S: A virtual environment for risk-management training based on human-activity models. Presence: Teleoperators and Virtual Environments, 22(1), 1-19. 
7. Verna, D. (2001) Virtual reality and tele-operation: a common framework, Proceedings of the 5th World Multi-Conference on Systemics, Cybernetics and Informatics (SCI)-Emergent Computing and Virtual Engineering, 3, pp. 499504.

8. Beauchesne, M.-N. (1985) La formation, conditionnement ou appropriation? : rflexion pour une dmarche pdagogique partir de lexprience : un exemple, la formation lanalyse des conditions de travail. Edited by ditions de lUniversit de Bruxelles ; Institut de sociologie.

9. Fuchs, P., Moreau, G., and Guitton, P. (Eds.). (2011). Virtual reality: concepts and technologies. CRC Press.

10. Cherrett, T. et al. (2009) Making training more cognitively effective: Making videos interactive, British Journal of Educational Technology, 40(6), pp. 11241134.

11. Kozak J., J. et al. (1993) Transfer of training from virtual reaality, Ergonomics, pp. 777784 .

12. Dris, A.-S., Gouranton, V. and Arnaldi, B. (2016) Integration concept and model of Industry Foundation Classes (IFC) for interactive virtual environments.

13. N. F. Noy and D. L. McGuinness. (2001) Ontology development 101: A guide to creating your first ontology. Technical report, KSL-01-05, Stanford Knowledge Systems Laboratory.

14. Zhang, L. and Issa, R. (2011) Development of IFC-based construction industry ontology for information retrieval from IFC Models, Proceedings of the 2011 eg-ice , (January 2015).

15. Raja R. A. Issa and Ivan Mutis (2015) 'Ontology in the AEC Industry: A Decade of Research and Development in Architecture, Engineering, and Construction'

16. Kreider, R. G. (2013) An Ontology of the Uses of Building Information Modeling, (December), p. 198.

17. Kreider, R. and Messner, J. (2015) A Model Use Ontology 1 Introduction : The Need for a Model Use Ontology.

18. Tibaut, A. et al. (2018) Ontologizing the Heritage Building Domain, 10754(January).

19. Zhang, L. and Issa, R. (2011) Development of IFC-based construction industry ontology for information retrieval from IFC Models, Proceedings of the 2011 eg-ice , (January 2015).

20. Costin, A. and Eastman,C. (2017). 'Requirements for Ontology Development in the AECO Industry'. In: LC3 2017: Volume 1 - Proceedings of the Joint Conference on Computing in Construction (JC3), July 4-7, 2017, Heraklion, Greece, pp. 553-540.

21. Beetz, J., Van Leeuwen, J., and De Vries, B. (2009). IfcOWL: A case of transforming EXPRESS schemas into ontologies. Ai Edam, 23(1), 89-101.

22. buildingSMART Data Dictionary. ISO 12006-3 based ontology for the building and construction industry. url: http://bsdd.buildingsmart.org/

23. OmniClass Construction Classification System. A classification system for the construction industry. url: http://www.omniclass.org/

24. Claude, G. et al. (2014) Short Paper : \# SEVEN, a Sensor Effector Based Scenarios Model for Driving Collaborative Virtual Environment, pp. 14.

25. Chellali, A., Dumas, C. and Milleville-Pennel, I. (2012) Haptic Communication to Support Biopsy Procedures Learning in Virtual Environments, Presence: Teleoperators and Virtual Environments, 21(4), pp. 470489.

26. Churchill, E.F. and Snowdon, D. (1998) 'Collaborative virtual environments: An introductory review of issues and systems'.

27. buildingSMART. The worldwide authority driving the transformation of the built asset economy through creation \& adoption of open, international standards. url:https://www.buildingsmart.org/ 